\title{
Changes in joint laxity occurring during pregnancy
}

\author{
M. CALGUNERI, H. A. BIRD, AND V. WRIGHT \\ From the Rheumatism Research Unit, University Department of Medicine, General Infirmary at Leeds, and the \\ Royal Bath Hospital, Harrogate
}

SUMMARY We have studied changes in peripheral joint laxity occurring during pregnancy in 68 females using both the finger hyperextensometer to quantify laxity at the metacarpophalangeal joint of the index finger and Beighton et al.'s modification of the Carter and Wilkinson scoring system. Although the latter system recorded no change, the more sensitive hyperextensometer demonstrated a significant increase in joint laxity during the last trimester of pregnancy $(0 \cdot 02>p>0 \cdot 01)$ over the readings from the same individuals after parturition. When primigravidae and multigravidae were compared, a highly significant increase in laxity was found in women having their second baby over those having their first $(0 \cdot 01>p>0 \cdot 001)$, though no further increase in laxity occurred in subsequent pregnancies.

Relaxation of the pelvic joints is an essential and normal accompaniment of pregnancy and may be related to hormonal changes. Abramson et al. ${ }^{1}$ noted relaxation of the symphysis pubis in women, beginning in the first half of pregnancy and increasing during the last 3 months, with subsequent return to normal that started soon after delivery and was complete within 3 to 5 months. These changes correlate with levels of the hormone relaxin, which increase 10 -fold during pregnancy, reaching a maximum at 38-42 weeks. ${ }^{2}$ However, it is possible that other hormones, including progestogens and endogenous cortisol, may also play a part.

Epidemiological surveys ${ }^{3-6}$ show more pronounced generalised joint laxity in females than in males of the same age. Anecdotally this difference is ascribed to the need for 'lax ligaments' in pregnancy, though to our knowledge there have been no studies of changes in peripheral joint laxity during pregnancy. We have therefore quantified peripheral joint laxity in a group of 68 females both during pregnancy and after delivery, each subject acting as her own control.

\section{Subjects and methods}

Sixty-eight pregnant women attending the Antenatal Clinic at the Maternity Hospital, Hyde Terrace, Leeds, were studied. The mean age was $27 \cdot 16$ years (range 18-40). Thirty-five were primigravidae and 33 multigravidae. The first assessment was per-

Accepted for publication 22 October 1980.

Correspondence to Dr H. A. Bird, Clinical Pharmacology Unit, Royal Bath Hospital, Cornwall Road, Harrogate HG1 2PS. formed on each subject between the 24th and 40th week of pregnancy (mean 33.0 weeks). This was on a routine antenatal clinic visit. The second assessment was performed on each individual at home between 5 and 25 weeks after delivery (mean $15 \cdot 1$ weeks).

On each occasion generalised joint laxity was assessed by Beighton et al.'s modification ${ }^{3}$ of the scoring system of Carter and Wilkinson ${ }^{7}$ and extension of the metacarpophalangeal (MCP) joint of the left index finger was quantified with the finger hyperextensometer of Jobbins $e$ t al., with all the precautions previously described. ${ }^{8}$ Reproducibility of the machine was found to be $\pm 2^{\circ}$, and the preset torque remained unaltered during the period of the study.

Student's $t$ test was used in the statistical analysis.

\section{Results}

Since laxity may fall with age at certain joints, the population was divided into 5 age groups (less than $22 ; 22-25 ; 26-28 ; 29-31 ; 32$ or greater). The mean hyperextensometer reading after delivery for each of these groups was $65,63,63,65$, and 67 degrees respectively. It was concluded that there was little natural reduction in laxity within this age group, and no subsequent correction factor was applied because of age.

Mean value for joint laxity during and after pregnancy for the 2 scoring methods used are shown in Table 1. No significant change occurred in laxity assessed by the Beighton scoring system, though the more precise hyperextensometer showed a higher degree of hyperextension at the MCP joint during 
Table 1 Comparison of joint laxity during and after pregnancy in 68 females

\begin{tabular}{llll}
\hline $\begin{array}{l}\text { Assessment of } \\
\text { joint laxity }\end{array}$ & $\begin{array}{l}\text { During } \\
\text { pregnancy } \\
(\text { mean } \pm S D)\end{array}$ & $\begin{array}{l}\text { After delivery } \\
(\text { mean } \pm S D)\end{array}$ & $\begin{array}{l}\text { Statistical } \\
\text { significance }\end{array}$ \\
\hline $\begin{array}{l}\text { Generalised joint } \\
\text { laxity score }\end{array}$ & $3 \cdot 3 \pm 2 \cdot 5$ & $3 \cdot 5 \pm 2 \cdot 5$ & $\mathrm{NS}$ \\
$\begin{array}{l}\text { Finger } \\
\text { hyperextensometer } \\
\text { readings (degrees) }\end{array}$ & $70 \pm 15$ & $65 \pm 13$ & $0 \cdot 02>\mathrm{p}>0.01$ \\
\hline
\end{tabular}

pregnancy compared with readings after delivery, and this was statistically significant. The degree of hyperextension at the MCP joint was then correlated with the duration of pregnancy. There was a slight trend for readings to be highest between the 28th and 30th week, though at no time was there a significant difference from any other time during the period of pregnancy studied. Hyperextension at the MCP joint was then analysed in relation to the number of previous pregnancies. The results of this are shown in Table 2 . Although all 3 groups studied were assessed at a comparable period during the pregnancy (column 2 ) there is a highly significant difference in the degree of hyperextension between primigravidae and multigravidae.

Since there is some evidence that inherited hyperlaxity prevents the formation of abdominal striae after delivery, the abdomen of all subjects was examined on the second assessment. Forty-one subjects displayed striae and 27 subjects had none. There was no significant difference in the mean hyperextensometer reading between these groups, either during or after pregnancy $\left(71^{\circ} / 65^{\circ}\right.$ and $70^{\circ} / 64^{\circ}$ respectively).

\section{Discussion}

Our results demonstrate the value of mechnical devices for the accurate quantification of joint laxity. Though in the study of generalised joint hyperlaxity measurement at the MCP joint of the index finger correlates relatively poorly ${ }^{9}$ with global assessments such as the Carter and Wilkinson scoring system, in the study of serial change in joint laxity in a normal population the hyperextensometer has proved capable of detecting small degrees of change.

While changes occurring in the symphysis pubis of women during pregnancy were well documented before the hazards of $x$-rays were realised ${ }^{1}$ (Scott J S, unpublished, 1955), we know of no previous studies of peripheral joints during pregnancy apart from a relatively subjective study on ligamentous instability in the knee in women after childbirth. ${ }^{10}$ Our results demonstrate a generalised change in laxity, presumably hormone mediated, in addition to local changes that may occur in the pelvic ligaments, where postural factors and pressure may be important. Whether our results should be attributed to relaxin or to altered steroid metabolism remains unclear.

Our results strongly suggest maximum laxity is obtained during the second rather than the first pregnancy. It does not increase thereafter. Future prospective studies of multiparous women are likely to confirm this. Our results also suggest that the presumed hormone mediated change in collagen observed is only temporary, both primigravidae and multigravidae reverting to normal after delivery. However, studies to ascertain whether the normal reduction in joint laxity with age is less pronounced in multiparous women would be of interest.

Since the laxity of collagen can be altered by circulating hormones, this may present therapeutic possibilities in the treatment of rheumatic disorders characterised by 'hardening' of collagen. Although diseases such as scleroderma fail to improve with steroids, the use of relaxin, or analogues of this hormone, may be worthy of study.

We thank Professor J. S. Scott, Mr J. R. Peel, Mr R. R. Macdonald, and $\mathrm{Mr} \mathrm{K}$. W. Hancock for allowing us to study patients under their care.

Thanks are also given to $\mathrm{Mr} \mathrm{A}$. Moreton for technical assistance and the late Mrs. J. Battersby for secretarial help.

\section{References}

${ }^{1}$ Abramson D, Roberts S M, Wilson P D. Relaxation of the pelvic joints in pregnancy. Surg Gynecol Obstet 1934; 58: 595-613.

${ }^{2}$ Zarrow M, Holmstrom E G, Salhanick H A. The concentration of relaxin in the blood serum and other tissues of women during pregnancy.J Clin Endocrinol 1955; 15: 22-17.

3 Beighton P H, Soloman L, Soskolne C L. Articular mobility in an African population. Ann Rheum Dis 1973; 32: 413-8.

${ }^{4}$ Harris H, Joseph J. Variation and extension of the metacarpophalangeal and interphalangeal joints of the thumb.J Bone Joint Surg 1949; 31B: 547-59.

Table 2 Mean change in hyperextension of MCP joint during pregnancy in primigravidae and multigravidae

\begin{tabular}{llll}
\hline $\begin{array}{l}\text { Number of previous } \\
\text { pregnancies (excluding } \\
\text { miscarriages) }\end{array}$ & Number of subjects & $\begin{array}{l}\text { Mean antenatal assessment } \\
\text { (weeks) }\end{array}$ & $\begin{array}{l}\text { Mean increase in } \\
\text { hyperextension MCP joint } \\
\text { during pregnancy (degrees) }\end{array}$ \\
\hline 0 & 37 & $33 \cdot 8$ & $3 \cdot 9$ \\
1 & 19 & $32 \cdot 2$ & $8 \cdot 9$ \\
$2 / 3$ & $10 / 2$ & $32 \cdot 1$ & $8 \cdot 3$ \\
\hline
\end{tabular}


${ }^{5}$ Wynne-Davies R. Acetabular dysphasia and familial joint laxity. $J$ Bone Joint Surg 1970; 52B: 704-16.

${ }^{6}$ Loebl W. Assessment of mobility of metacarpophalangeal joints. Rheumatol Phys Med 1972; 11: 365-79.

' Carter C, Wilkinson J. Persistent joint laxity and congenital dislocation of the hip. J Bone Joint Surg 1964; 46B: 40-5.
8 Jobbins B, Bird H A, Wright V. A joint hyperextensometer for the quantification of joint laxity. Engineering Med 1979; 8: 103-4.

- Bird H A, Brodie D A, Wright V. Quantification of joint laxity. Rheumatol Rehabil 1979; 18: 161-6.

${ }^{10} \mathrm{Klein} \mathrm{K}$. The effect of parturition on ligament stability of the knee in female subjects and its potential for traumatic arthritic change. Am Correct Ther J 1972; 26: 43-5. 